\title{
Metaphors for the Meaning of Caring for a Spouse with Dementia
}

This article was published in the following Dove Press journal:

Journal of Multidisciplinary Healthcare

\author{
Kirsten Thorsen ${ }^{1,2}$ \\ Aud Johannessen ${ }^{1,3}$
}

'Norwegian National Advisory Unit on Ageing and Health, Vestfold Hospital Trust, Tønsberg, Norway; ${ }^{2}$ Norwegian Social Research (NOVA), Oslo Metropolitan University, Oslo, Norway; ${ }^{3}$ Department of Nursing and Health Sciences, Faculty of Health and Social Sciences, University of South-Eastern Norway
Correspondence: Aud Johannessen Norwegian National Advisory Unit on Ageing and Health, Vestfold Hospital Trust, P.O. Box 2136 NO-3103, Tønsberg, Norway

Tel +47 97547979

Email aud.johannessen@aldringoghelse.no
Background: Spouses of people with young-onset frontotemporal dementia (YO-FTD) (age 65 years or younger) encounter special challenges. The diagnosis is scarcely known; the early onset is unexpected; and the disease is characterized by symptoms varying from those of other types of dementia. Caring implies increasing hardships, which can be difficult to communicate to others when applying for support. Metaphors create and communicate meaning and are increasingly used in health care and health interventions as ways to better understand the situation.

Aim: To examine the experiences of spouses of people with YO-FTD and their needs for care and support as expressed through metaphors in narratives of their experiences during the development of the dementia.

Methods: Qualitative interviews with 16 informants (ten women, six men) were conducted in $2014 / 2015$. They were recruited from seven memory clinics, one municipality dementia team, and a nursing home. Steger's three-step method for analyzing metaphors was applied. Findings: The core metaphors cover experiences of the dementia and the transformation of the spouse, changed roles and relationships between spouses, the transformation of the self, a radical turn of existential life, and relationships with others. Metaphors are words and phrases used to talk about complicated, contradictory, shameful, and/or normatively difficult feelings and reactions as caring spouses. The open themes and, at the same time, provide verbal shields and defences. Metaphors are especially effective for expressing the strength of the reactions in caring as emotional work and are tools for mastering emotions and challenges in life.

Conclusion: Metaphors give insights into the significant experiences of spouses of partners with YO-FTD and offer personnel in health services a better understanding of their needs for tailored support and help.

Keywords: communication, early-onset, narratives, spouses, frontotemporal dementia, qualitative method

\section{Introduction}

Spouses of people with young-onset dementia (YOD) (age 65 years or younger) experience extraordinary challenges, especially when the diagnosis is frontotemporal dementia (FTD). The disease disrupts the life course of the people involved, destroying working careers, inflicting harm on family relationships, and erasing ageing prospects. The future is shortened and possible positive aspects of ageing, ${ }^{1}$ with "freedom" from responsibilities in early retirement, disappear. The situation changes to what has been called "a torment", turning life upside down. ${ }^{2}$

To be able to provide tailored care and support for the family, health personnel must listen to their stories - not only to what is said openly but also to what is said 
implicitly and allegorically. Thoughts about and feelings toward an ill spouse may be contradictory, shameful and even culturally rejected, breaking the norms of an enduring relationship of love. The ideal of faithful love and care also extends to 'difficult times' during hardships caused by serious diseases and disabilities. Metaphors can serve as tools for talking about shameful, complicated and conflicting feelings, disguised by the camouflage of words from other spheres. What are the motivations and resources for caring, the resilience and the breaking point of experiences of burden? Sensitizing our attention to metaphors can be a vehicle for better understanding the experiences, meanings and challenges of caring for a spouse with YO-FTD.

\section{Dementias and Younger People with Frontotemporal Dementia}

The syndrome of dementia is increasing worldwide, ${ }^{3}$ along with the ageing of populations, especially in the industrialized world. The syndrome is an umbrella term for various progressive cognitive diseases. While these are, at present, incurable, medication may mitigate symptoms, ${ }^{3,4}$ and care may improve well-being. ${ }^{3,4}$ To be given a diagnosis for a progressive lethal disease with no hope of recovery is a hard message not only for the patient but also for his or her family, who foresee years of increasing caregiving and transformed relationships. ${ }^{2,5,6}$ Dementia is typically an "old-age disease" and is considered such, increasing in prevalence and incidence with advancing age. However, some people develop dementia at a rather young age (age 65 years or younger), some even in their 40s, when the disease is unexpected, unusual and, thus, often recognized and diagnosed rather late even by the medical profession. $^{2,7-9}$ The incidence of dementia in the age group 65 years or younger in Norway, with a population of 5 million people, is estimated to be at least 4500; estimates vary from 11 to almost 27 per 100,000 people. $^{10,11}$ The most common types of dementia in this age group are Alzheimer's disease (YO-AD) and frontotemporal dementia (YO-FTD), a term for several uncommon disorders that primarily affect the frontal and temporal lobes of the brain. The symptoms are described mainly by the frontal syndrome and include lack of initiative, withdrawal, loss of inhibitions, decreasing abilities to solve problems and disturbances in verbal abilities. ${ }^{4,12}$

Frontotemporal dementia is more prevalent among younger people with dementia than older, and appears in nearly equal distribution in men and women. ${ }^{13}$
A Norwegian study ${ }^{14}$ with people with YO-FTD showed the average age at onset to be 52.8 years. In Norway and elsewhere, people with YO-FTD do not represent a large group, but they and their families encounter great challenges and extraordinary demands. ${ }^{2,15,16}$

Compared to people with YO-AD, people with YOFTD often show a change in their personality, and they have less insight into their own situation. Moreover, carers for people with YO-FTD experience greater distress than other carers due to the patients' erratic behaviour. ${ }^{17,18}$ The condition of a younger adult with dementia will have a significant impact on the whole family, characterized by increasing caregiving tasks, stigma, and increased anxiety and depression, especially among the spouses of those with YO-FTD. ${ }^{19-23}$ Problems and distress are found not only in later stages of the dementia but also in earlier stages and during the process of establishing a diagnosis, especially a YO-FTD diagnosis. ${ }^{2,7,18,24-26}$

Review articles show that, thus far, there has been little research focusing on the carers' experiences and coping efforts to manage living with a person with frontotemporal dementia and how the situation influences their life. ${ }^{21,22,27}$ To the best of our knowledge, research on the needs of spouses of people with YO-FTD is even scarcer. A compelling requirement is to increase knowledge about the spouses' situation in order to be able to meet their needs for care and support in a person-centred approach related to their living situation. ${ }^{28}$

With this background, we have conducted the present study aiming to examine the experiences of spouses of people with YO-FTD and their needs through metaphors in narratives about their situation during the development of the dementia.

The article is based on a reanalysis of the data material concentrating on the participants' use of metaphors. A thematic analysis of the spouses' experiences and their need for care and support, and the implications for the health- and caring system is presented in an earlier article. ${ }^{2}$

\section{Metaphors}

Ricoeur $^{29}$ revealed how people use their linguistic imaginations to create and recreate meaning through metaphors. Generally, the essence of metaphors is understanding and experiencing one kind of thing in terms of another. In their pioneering work Metaphors We Live By, ${ }^{30}$ Lakoff and Johnson $^{30}$ underline that metaphors are pervasive in everyday life, not just in language but in thought and action as well. "Our ordinary conceptual system is fundamentally 
metaphorical in nature" (p. 3). Thus, metaphors play a central role in defining and describing our everyday realities, our experiences, emotions and actions. They indicate happiness and sorrows, health and illness, and mastery and misery for us as well as others.

In fact, metaphors are so prevalent in everyday language that they often go unrecognized and seem selfevident. Metaphors are varied; they may be conventional but can also demonstrate fantasy and present powerful images. Metaphors are also called "verbal pictures". ${ }^{31}$ Lakoff and Johnson, ${ }^{30}$ in their cognitive-semantic theory of metaphorical concepts, introduced a typology of metaphors: structural, orienting, ontological and new metaphors. Structural and orienting metaphors are basic ways of ordering the world around us and include directions, sizes and speeds. Ontological metaphors are ways of viewing events, emotions and ideas; these are the metaphors that are most frequently related to the experiences of being a spouse of a person with dementia. Metaphors are often conventions - cultural and stereotypical ways of describing events and things - but they are applied individually. ${ }^{32}$ However, they may also signify fantasy, originality and the transgression of norms.

Metaphors may construct and communicate realities in "subjective, yet psychologically powerful ways" (p. 372). ${ }^{33}$ Increasingly, they are introduced as tools in health care and mental health interventions. Therapists and clients often struggle to find words to convey "difficult to describe sensations, emotions, psychological states, and views of the self" (p. 251). ${ }^{34}$

Metaphors have been described as "a lens" into the narrator's emotions, beliefs and self-concepts. ${ }^{35}$ They are prevalent in medical discourse and health evaluations. A basic conceptualization is that "up" is good and "down" is bad; two examples are "He is in top shape" and "She is in high spirits" (p. 15), and these can be contrasted with examples such as "I am feeling down", "I am depressed", "Her health is declining", and "He dropped dead". ${ }^{30}$ Sontag has analysed their use in her book Illness as Metaphor. ${ }^{36}$ Metaphors may be fundamental to people for perceiving and defining symptoms and reactions and motivating them to seek care. ${ }^{37}$ Moreover, they can be integrated into therapy sessions to bring about positive change (p. 372). ${ }^{33}$ A contextual turn in the study of metaphors focuses on how metaphors function in various therapeutic work contexts and circumstances. ${ }^{33,38}$ Research examines how metaphors can address "realworld" concerns in substantial ways. ${ }^{39}$ These approaches are presented as the most promising trend for further research into health and illness metaphors. Some studies have examined metaphors related to dementia, concentrating on how people with dementia in metaphors describe experiences of attitudes and stigma connected to the disease or how dementia diseases are depicted by metaphors in cultural presentations, like films, reports, etc. We have found no studies focusing on metaphors in stories about experiences of caring for people with dementia, nor more specific studies on special groups of caregivers.

Metaphors make it possible for caregivers of people with dementia to allude to private and sensitive experiences and thoughts without revealing details. They may offer openings- lenses - for themes but can also provide protective shields - defences - without giving too much away and may be tools for mastering challenges in life. Furthermore, they may provide insights and information into significant experiences and offer people in the health services more varied leads into patients' and their families' needs for support and help.

\section{Methodology \\ Design}

The study is an interview study, and the design of the study represents a narrative qualitative hermeneutical approach, ${ }^{40,41}$ considered a fruitful way to capture experiences and needs for assistance in the daily lives of spouses of people with YO-FTD during the progression of the disorder. The method has the advantage of exploring the life world of the participants and the ways they experience, give meaning to, and narrate their feelings and cognitions. A narrative method is an approach that elicits stories and events. $^{42}$

\section{Participants}

The criterion for inclusion was that the participants should be a spouse or a cohabitant of people with YOFTD. All spouses/cohabitants were informed about their partner's diagnosis by a psychiatrist or geriatrician at a memory clinic. They were recruited from seven memory clinics, one municipality dementia team, and a nursing home designed to provide care for people with young-onset dementia. To increase heterogeneity, health personnel at these services contacted 17 spouses/ cohabitants of people with YO-FTD and asked them to participate. Thereafter, the author AJ contacted them to inform in more detail about the study and to recruit them to the project. One spouse declined to participate in this 
study. The people with YO-FTD were at different stages of the disease. The 16 participants were ten wives, five husbands and one male cohabitant. In the following text, spouses and the cohabitant are all denoted as spouses. The data were collected through individual qualitative interviews. Characteristics of the participants and the people with YO-FTD are described in Table 1. To vary the language, the included people will be referred to as spouses, husbands/wives, men/women, and participants.

Table 1 shows that the time since the diagnosis was confirmed, varied from zero to 11 years, and that the period during which the spouses recognized that "something was wrong" before the diagnosis was confirmed varied from one to 15 years. The total period of symptoms and illness ranges from three to 15 years. As indicated, the exact time of onset was often difficult to establish. Five of the ill spouses had moved permanently into nursing homes (three husbands and two wives) at the time of the interview, and one husband had died four months before the interview. The spouses are thus in different stages of caregiving. However, all of them have experienced at least three years of progression of the dementia. The one (a husband) with the shortest period has also experienced the stages of transference of the spouse to a nursing home.

\section{The Interviews}

A convenient place for each participant was chosen for the interviews, ${ }^{43-45}$ which took place in 2014 and 2015. Twelve of the interviews were conducted in the participants' homes, two at the interviewer's workplace, and two in a municipality office. The interviews were conducted by the second author, and they lasted from 31 to 79 minutes $($ mean $=57)$. They were tape-recorded and transcribed verbatim by a professional typist. A quality control check of the transcripts was performed by the interviewer listening to the tapes while reading the interviews. The interviews were based on an interview guide with six open-ended thematic questions that focus on the spouses' experiences of the development and progression of the dementia and living with a spouse having YO-FTD (Table 2). Depending on their replies, the aspects and ideas raised by the participants led to further questions to obtain additional information. Before the interviews, information about the spouse, the diagnosis, the progression of dementia, and the spouse's experiences with health services was collected by the second author (AJ).

\section{The Analysis}

We performed the analysis in line with the three-step analysis developed by Steger. ${ }^{46}$ The first step is metaphor identification and selection. The two authors were "parallel readers", as recommended by Steger, to broaden the scope of discovery and to compare and discuss the metaphors chosen. We especially sought for significant metaphors related to the life world and experiences of the caring spouse as we looked for repetition, elaboration, relatedness, contrast and emotion, as suggested by Steger. ${ }^{46}$ We focused less on conventional metaphors and structural and orienting metaphors, ${ }^{30}$ which were not directly relevant to our research questions. The two researchers reached consensus on most of the significant metaphors.

During the second step, we reflected upon and discussed the chosen metaphors in a more general context, including knowledge about people with young-onset frontotemporal dementia, the broader cultural and societal context for families living with a person with dementia, and services provided by the health and welfare system.

Then, at the third step, we returned to the original interviews to analyse the meaning and the implications of the metaphors in each participant's narratives about living as the spouse of a person with YO-FTD. More specifically, we were focusing on the functions the metaphors might have in the participants' presentations of their experiences and coping efforts.

We summarized our analysis as five main themes: the metaphors related to the participants' experiences of the dementia and the transformation of the spouse; the next themes were changed roles and relationships between the spouses and the transformation of the self, followed by a radical turn of existential life, and the last theme, the relationships with others.

\section{Ethics}

The study followed the ethics guidelines in the revised Declaration of Helsinki ${ }^{47}$ and those of the Regional Committee for Ethics in Medical Research, Southern Norway (number 2013/2149), and it was approved by the Norwegian Data Protection Authority (number 36,797). The participants received both oral and written information about the study beforehand and gave written informed consent before they were interviewed. 


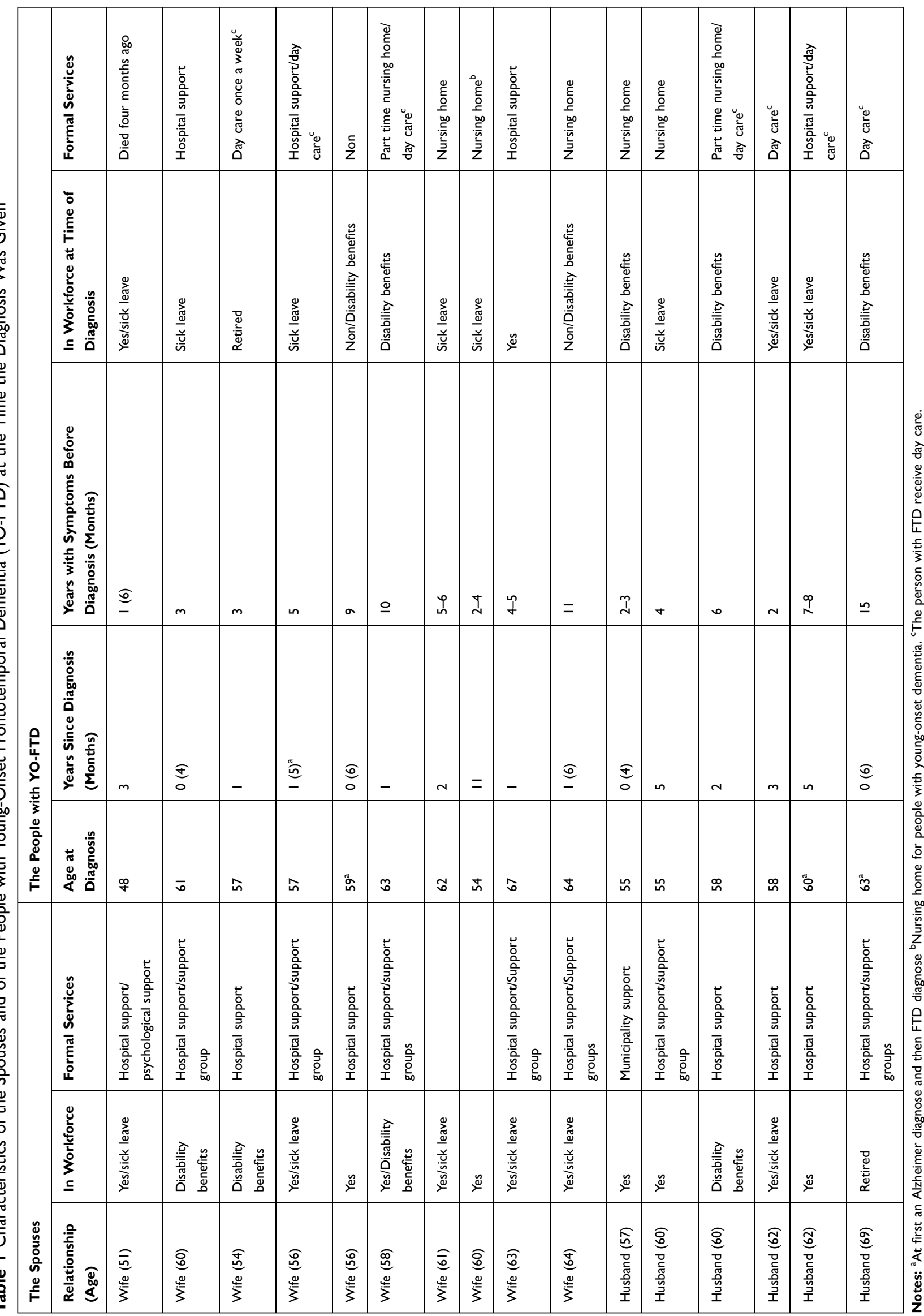


Table 2 Thematic Questions in the Interviews with Spouses of Younger People with Frontotemporal Dementia (YO-FTD)

\begin{tabular}{l} 
- How has it been these past years and how is it now for you having \\
a spouse with dementia? \\
\hline - How has the disorder affected your life? \\
\hline - How has the disorder affected your family and the relationships \\
within the family and among friends? \\
\hline - When you look back, is it possible for you to describe something \\
that has been or could have been of some help for you and your \\
family during the different stages of the disorder? \\
\hline - What kinds of support have you received, do you currently receive, \\
or are in need of today? \\
\hline - Have you had to make decisions for your spouse? \\
\hline
\end{tabular}

\section{Findings}

\section{Experiences of the Dementia and the Transformation} of the Spouse

The participants described the initial signs of their spouses' dementia as "strange behaviour". The spouse with dementia began acting in ways that differed from his or her ordinary patterns. A wife described her husband's behaviour as increasingly more erratic and unusual. He shopped excessively, which led to financial problems; he mixed day and night; he might repair his car or take his dog for a walk at night; and he lost his manners and habits. The spouse remarked, "You never knew what he was up to". He became more and more forgetful but also had some bright moments, which his spouse described with this metaphor: "He passed in and out of a bubble". The strange reactions did not indicate symptoms of an illness that the participants knew about and would have been alarmed by; they were simply beyond ordinary expectations and explanations. A wife called this period of confusing actions "a waiting room, and it went on for a very long time". A husband had recognized that his wife became more vulnerable emotionally, and he did not understand why. Spouses were reported to be more easily annoyed, irritated, and even aggressive, and this stage could develop over several years.

Receiving the diagnosis was referred to as a decisive moment. A woman stated that the time before the diagnosis was confirmed was a time "when I easily could have broken down". Metaphors referring to downward directions, like falling, indicated their emotional development. For several of the participants, getting the diagnosis was "a relief" - the situation became easier, the behaviour more understandable. The spouse's reactions could, thereafter, be seen through the lens of a disease metaphor. A participant described that receiving the diagnosis was "like getting to heaven". Being presented the diagnosis "was a moment when I fell completely into place", exclaimed another woman. The time before and after the diagnosis is contrasted by a husband in this way:

I experienced it (the situation) as difficult to cope with when I did not know the cause. You seek for it, don't understand, do not find reasons for the strange behaviour (...). Getting an explanation was a relief (...). For me, it was much easier to relate to the disease and to her when I knew what it was.

However, other participants saw the diagnosis as a catastrophe. A wife had noticed the first signs of strange behaviour about three years earlier. When her husband was no longer able to do errands, could not find his way, and forgot to turn off the car engine, she persuaded him to go see his doctor. He was assessed, and the dementia diagnosis was confirmed. She declared, "I turn 60 next summer. I can't understand it. I cannot believe it! That diagnosis! (crying). I think he is too fit for a diagnosis like that!' She sees a complete change in his personality: "He has always been the most patient man, avoided conflicts and fuss, and has never been impolite". Now he has started scolding her, has outbursts, and gets angry easily. She is scared:

I am very afraid for the future. Will I lose it? He is my best friend (crying). May I have no one left to talk to? He has been my anchor in life ... (it is) the unknown.

The metaphor of "anchor" in life, summarizes his former position for her. Without an anchor she is drifting without direction, living without a course and losing her feeling of security. To receive the diagnosis seemed to have given him a sense of relief. He has started on medication. She thinks he is less depressed, tired and exhausted. "He takes more initiative; things go on more easily; and his mind is brighter". Nevertheless, for her, his new personality and the diagnosis are a disaster.

In the later stages of the disease, the aggression and abuse of the spouse may be reduced; the vitality seems to be gone; and retraction and passivity, even apathy, increase. Metaphors allude to electricity, to lack of initiative and energy. A woman said, "He has no spark left. (...) Earlier, he was in a hurry. Now there is nothing, no interest left". Another woman remarked, 'At the hospital, they say 
"He lacks a start button". She says that her husband has "left her" in many ways. "He is so tired all the time. He sleeps, and sleeps, and sleeps". For the spouses, this stage means that the engagement in the relationship and the direct interaction between the spouses fade away. Another wife remarked, "I lost him several years ago".

One woman described a new experience of insecurity and how her feeling of safety is gone. Her husband has been a "pillar" in life, guided and supported her, and assured her that everything would be fine. The metaphor pillar coincide with the word anchor, describing how the husband earlier was assuring stability and security in her life. Now, he has transferred the responsibilities for tasks he can no longer manage to her. The support is gone. It is not just the losses and the hardships during the caring period that evoke despair but also the prospects for the future, foreseeing further decline and loss of the spouse in short, "the unknown".

The greatest hardships are seen among the spouses of individuals with frontotemporal dementia without insight into or acceptance of the disease and no admission of any mistakes or disabilities. All problems are caused by others, all mistakes are other people's faults. The diagnosis be a deceit, as a conspiracy between the spouse and the family doctor. The spouse becomes a traitor and an enemy, and the focus of a relentless fight. A wife stated that her husband received the diagnosis about a year ago, but the signs of personality changes appeared about three years earlier. She described his former personality as very focused on his job and less interested socially. "Then he became much angrier and more difficult at home". He shares the characteristics described by other spouses: eruptive anger, scolding, aggressive behaviour towards others, being self-centred, and lacking empathy and concern even for their children and grandchildren. In this case, the reactions were considered as exacerbations of former personality traits. After an outbreak of aggression during a holiday, she just "fell into the cellar", indicating deep depression. Then, she contacted his doctor, who did not believe her descriptions of his state; during consultations at his office, her husband appeared as quite another man.

Many told that the spouse's reactions could be quite the opposite of his or her former personality: "He has never been like this (...). Sometimes he is quite normal, suddenly everything is bundled up", informed one woman. "Everyday life becomes unpredictable", she continued. "The days are very different. Some days he manages much, other days nothing". When one wife was asked how she reacts when her husband has attacks of anger, she said, "It is terrible scolding. Everything we say or do is wrong, whatever when, where and how we say it. What to do? You just stay silent and take what comes". Another wife compared Alzheimer's dementia with the frontotemporal dementia of her husband: "It is like day and night. It is a world of difference". The metaphors of "day and night", "lightness and darkness", summarise the experiences of the changes of the spouse, the transformation. As day and night, the experiences are in total contrast, completely the opposite. The change in the spouse's personality seem to be besides any image of normal life. A woman exclaimed, 'It is outside any sense. It is not understandable! An expression I have used for his disease is "It is inexplicable"!

\section{Changed Roles and Relationships Between Spouses}

The spouses have gradually taken over the former responsibilities and tasks of the partner. He or she have lost the responsible aspects of an adult role in the partnership. The men must do more household chores, the women describe in more detail all the "men's work' they have taken over. One wife stated,

Now I also have to do everything with the house and the garden, calling in craftsmen, repairing the car, adding to all the rest of the household tasks. I do absolutely everything here.

The most prevalent metaphor used by the female participants about their spouse in later stages of the disease is the image of a child. The woman quoted above continued, "Then I have to look after him. I have to. See that he eats, washes himself and gets where he should go. It is just like having a child". She compared this situation to the reactions of her little granddaughter: "It is easier to explain to my grandchild, five years old. She remembers what I have said to her, while he forgets it immediately". None of the husbands compared their spouses to a child; the women have had the main caring responsibilities for children, and - as shown - some directly compare aspects of the caring role for the partner with YO-FTD to that of caring for children and grandchildren.

Another woman mentioned, "I have so many caring tasks that I have felt that he is more my child that my husband". She finds the situation surreal. It is so strange that she cannot describe or explain it to others.

Some participants attempt to preserve and demonstrate feelings of tenderness for a beloved spouse for a long time; 
they sit closely, pat and touch, and provide physical contact. However, the ill spouse becomes more and more remote as the dementia develops - it seems as he or she disappears, "drifts away". Being close and becoming distant are contradictory reactions and emotionally very stressful.

The metaphor of the spouse as a child is closely related to the concept of a patient. A woman no longer perceives her husband as a man or as a sexual partner: "I am looking at him more as a patient. And he is no longer interested (in sex)". The woman underlines that "It is not like him at all". At this stage, her husband, seen as a child and/or a patient, has no resemblance to her former spouse: "There is no human being behind any disease here, you see". With such a dehumanized picture and foreseeing his further deterioration, life does not seem worth living: "It is nearly so that I think it had been better if he was dead, both for him and for us. It is a terrible thing to say, but it is no life for him either". The situation may have reached the stage of being intolerable as it is described with the metaphor "a hell".

\section{The Transformation of the Self}

Along with the progression of the dementia, the caring spouse is transformed as well. The self - formerly experienced as a distinct individual with identity and personal interests - is now absorbed by the caring self. A core metaphor often used is "I have lost myself". One female participant reported that the psychologist recommended she "try to find myself during the mess, during all of this". Another woman commented, "I have tried to pull myself together". Her self-image is of an individual who is scattered and dispersed and whose self has disappeared.

The situation and the difficult challenges of everyday life may hit the self harshly - the caring person may come to a halt as seen in the comment: "Then I hit the wall, really (...). And then I just fell out." Others narrated their experiences as a kind of stepwise striving: "It has been having to take step by step", remarked one. "Everyone says that his life has been in steps, but so it has been for my life also", said another woman.

For many participants, a dominant feeling during the progression of the dementia is of "being tied up" or being "bound" by caring for the spouse. The challenge has been "to tie up everything" and a dominant wish is "to shut out everything and just be myself", as one woman remarked. The time the spouse is away is described by the words "free time" or a "free minute". It may be rather brief moments, as noted in this comment: "It is the short time before I fall asleep in the evening".

Waiting for an outburst, striving to stay calm and patient and avoiding becoming irritated are exhausting. One spouse commented, You get tired, not physically, but psychologically, when you go on tip-toeing all the time. You must weigh everything you say on a gold scale, and you nearly ... Well, you are not in constant anxiety, but it ... is hanging over you all the time. Suddenly it blows up.

Another woman presented a metaphor of "extinguishing fires" to describe her reactions when the outbursts come: "I just have to extinguish fires here when they come, in one way or another". She has the feeling that that her total life has been lost; she is no longer living: "What is so bad is that you don't live. You get your life ruined. (...) It is a terrible hardship that you cannot do anything. Nothing at all!' Her life is in limbo. She describes that she is not the roles that she has had to assume: "We are married, but I am not a nurse; I am not a mother; and I am not a housekeeper. As I say, for many years my life was put aside, so to say". That her own life has been put aside is also her summary of the situation at the end of the interview. Her husband has recently moved into a permanent place at a nursing home. She praised the personnel she has met at the institution, saying, "They have been very concerned that I start living my own life", and she expressed the relief she felt when he moved into the nursing home:

I was so fed up. I just thought, if one day I could be allowed to be alone. Just that! That day my son and I just sat here and were completely 'set out'. Ah, at last! We cross our fingers that we will have no more (...). They (the men) can just move out, but we female folks have a conscience, you know.

The woman imagines that men leave their partners with dementia more easily than women do; women stay and take on their obligations as caregivers for their spouses with dementia. She values what the health personnel say to her, "Now you shall live your own life, we take care of him". She shall regain herself.

Some spouses have been able to continue to work fulltime or part-time due to flexible arrangements at work and day care for the spouse. A woman said, "In all these years, if I had not been able to walk away and think 'Now I go to my life', I would not have been able to keep him at home for such a long time". 
One man described the experience of getting his life back when his spouse moved into a nursing home. He was relieved when the diagnosis was confirmed; he continued his work and was quickly offered a respite leave in a nursing home for his wife, which became a permanent residence. Life has now taken a new turn; he reported that his life has returned to "normality" and "freedom":

Suddenly having the freedom of being able to do things on your own and start living a normal life, it was great. A relief, really. Let go of the responsibility for an ill person. I had no ... (regret). I was so prepared for it that I had no problems letting her go.

The diagnosis and the new definition of his wife as a patient eased his feelings when he decided to move her to a nursing home. His responsibility and role in the decision disappears in the medical discourse of his wife as a patient.

For others, their spouse's situation continued to dominate their life, even after the spouse was moved into a nursing home. One wife noted that, at the nursing home, her husband was asked if he missed something. She stated, "He answered, 'I miss my wife', and it went straight to my heart. It did not reduce my guilty conscience that I had sent him away".

\section{A Radical Turn of Existential Life}

What metaphors are applied to condense and convey the influence that the dementia has had on the caring spouse's total experience of life? The stories are told in retrospect, and the initial questions were intended to invite a chronological narrative, starting with the onset of the dementia disease, as registered by the spouse. However, several participants quickly lapsed into their descriptions of the total situation and their intense feelings of misery. A woman described the situation as a permanent grief: "It is just grief all the time. I do not see anything .... (...). I am not fine at all. Nothing at all! Really!"

The impact of the progression of the disease and the experience of being informed about the diagnosis are described as a radical turn of existential life. A wife, crying at the start of the interview, said, "Really, it is turning the whole life upside-down (...). It is somewhat of a transformation. It is disastrous." According to her, her husband has "been ill for three, maybe four, or at least five years". She cannot say more exactly when the changes in her husband began; the development was nearly imperceptible but drastic in the long-term consequences. Her spouse has a combination of frontotemporal dementia and
Alzheimer's disease. When asked how these years with his disease have been, she answered bluntly, "Complete hell, to say it mildly (crying). You see, I have had some days being deep down. It is terrible". The phrase "turning life upside-down" describes the total transformation of all aspects of her former life.

When the disease has reached its later stages, clock time and reaching a limit or a top are presented as appropriate metaphors: "Everything has gone half past eleven". Episodes of aggression, violence or improper scolding or anger may be turning points, a push for decision-making. One spouse stated, "It just went over the top for both my son and me. Now, we can't stand it any longer. It just must stop'. Another one commented, "He is not able to understand that he has passed a limit". Thus, the metaphors of reaching and passing a limit also signify that the spouse will consider a change or will seek to end an intolerable situation.

\section{Relationships with Others}

Core metaphors for relationships with others varied along the dimension "open-closed". A husband remarked, "She is very open about it (the disease), and then we also are open”. A wife described having been open about her husband's illness by using the metaphor "I have called a spade for a spade". Spouses who have shown no recognition or admittance of illness may be resolute in wanting to hide their shortcomings and disabilities from others. A woman remarked that her husband is "very closed towards his friends". She characterized him as "strong-willed" and noted that he is adamant about not revealing the signs of dementia, which he sees as disabilities, to others. According to her, he is very clever and can "pull himself together" and is quite proficient at pretending to be himself as he was before the illness struck. However, afterwards he just collapses.

Many of the participants have gradually lost contact with friends and some family members. Keeping in touch has become increasingly more difficult with the progression of the disease, especially because of the communication problems. Also, the spouses with dementia may use metaphors when they miss words. A wife remarked that when her husband has forgotten the names of acquaintances, he may call them "Miss Piggy" or "Fatty". Even being open about the cause of such behaviour and the disease, the communication becomes too strained.

Some good friends and close family members may continue to be trusted and supportive. Spending time 
with these confidants is the opposite of "hell" or "darkness"; one spouse stated, "It is gold, you know, to get away with my very good friends". Spouses see and live with the struggles and the difficult times for their mates, but there are also moments of joy and pleasure. One spouse commented, "If she seems depressed and one of the grandchildren arrives, it is like the sun shines at once".

When the dementia is not associated with the typical memory reduction of Alzheimer's disease, even the nearest family members - such as the spouse's parents or siblings - may not recognize the disease, the changed personality and the reduced abilities. A wife noted that she has had to hide her problems from her old mother-inlaw in order to protect her. To accomplish this, the wife has had to make excuses for her husband and find explanations for his behaviour, noting, "I can't stand it. When we have been open to all our friends, why do we have to conceal it from her?' The burden of being the victim of aggression and, at the same time, having to hide or excuse the aggressive behaviour, being "closed", is intolerable.

The well spouse may be accused of causing the ill spouse's mistakes or aggressive behaviour. A family doctor saw no reason for more hours of respite care and told the patient's wife, "If you reduce the stress when he is at home, he will be quite fine. He is quite okay when he is on relief". The husband's doctor explained to her: "It is typical for frontotemporal dementia that strict and clear frames do function. When they know that there is no leeway". "Of course, they have regulations there (at the nursing home), but that is impossible at home", she commented. At home there is "a mess", at the nursing home there are rules, no "leeway".

For some, the decision to apply for a nursing home has been extremely difficult and fraught with guilt, hesitation and indecision. A woman said that she "kept her husband at home" one month after he had been offered a place in a nursing home:

I was not able to let him go. It was incredibly difficult for me. I should have had someone to support me. I felt extremely guilty. I visited him often, and every time I left, he wanted to go with me. I sat in my car, crying (...). I felt very wicked and very small.

However, the process of moving can turn out to be quite different from what was feared. A couple received the message that the husband had been offered a permanent place in a nursing home. The wife accompanied him to the nursing home to show him around. She observed, on the first day there, he shone like the sun when they warmly 'welcomed' him, all these young, nice women, you know. Yes, he really sparked, which very rarely happens.

During his last month at home, she had not been able to leave him alone at all. For her, the sun in his face has reassured her that the nursing home will be a good solution for both. "Sun" and "light" are core metaphors for positive sides of life, good moments. These are often referring to situations outside the partnership, where every-day hassles and conflicts may dominate the relationship.

Certainly, there are positive aspects of caring. Research are referring to caring of people with Alzheimer's. However, the early stages of the dementia disease vary a lot; the sneaking signs of memory deficiencies of older people with Alzheimer's dementia are very different from the situation in the first stages of FTD in younger people. Concern, gratitude and empathy - leading to good moments - are more rare in the spousal care for people with YO-FTD. Positive aspects of caring may also be fulfilling the caring duty even in hardships, and bad conscience be the negative consequence of neglect or a feeling of not being able to give enough.

We do not find any substantial difference in the metaphors used by people with shorter or longer periods of care. Also, those who have experienced a transfer of the spouse to a nursing home describe vividly their experiences during the dementia development. They report their feelings and the situation leading to the decision to end their caring at home, pointing at their "limits" and passing "a top".

The core metaphor both for private assistance - which is appreciated but insufficient - and public support is relief. The word is also an administrative concept for some types of public help offered to this group, such as day care centres and intermittent respite care. Other more general types of assistance are home nursing, home help and support contact. The assistance the spouses need is described in greater detail in the interviews but with rather few metaphors. For precise descriptions of the types of public support, other more concrete words are chosen and are more adequate. Metaphors are the focus for feelings and are expressing the intensity of the feelings.

\section{Discussion}

We have performed an analysis of the use of metaphors in the narratives of spouses of people with YO-FTD focusing on "The stories metaphors tell" ${ }^{46}$ Our study of the 
experiences of spouses with YO-FTD gives knowledge about an exceptionally demanding caring situation. The basic result is that, among spouses of people with YOFTD, metaphors give opportunities for expressing strong emotions and emphasizing the strength of one's feelings. The respondents used metaphors to discuss thoughts and reactions that might be hidden, considered taboo and societally forbidden - and difficult to talk about. Metaphors offer the spouses "verbal camouflage" when presenting their reactions to others. As Steger formulated it, metaphors are tools "to decipher tacit aspects in narratives". ${ }^{46} \mathrm{He}$ introduced the concept "root metaphors" as more general metaphors for the situation, metaphors that primarily function as "action generators", stirring handling. We prefer and have applied the concept "core metaphor" to designate the individual's most significant metaphors characterizing their experiences, perceptions and reactions to a life with a spouse afflicted with frontotemporal dementia. ${ }^{46}$ Core metaphors are constituent metaphors for this person's individual experiences and are used to condense feelings, thoughts and reactions, and may initiate action. ${ }^{37}$

We explored the narratives for repetition, elaboration, relatedness, contrast and emotion in the most significant metaphors, ${ }^{46}$ indicating speakers' existential feelings The ontological metaphors. ${ }^{30}$ The core metaphors may be paired and contrasted.

As demonstrated, two of the most constituent and contrasting core metaphors are "heaven" and "hell". They point to strongly felt existential experiences that are beyond mundane everyday life and a normal expected life course. The religious vocabulary is referring to spheres outside human experiences on Earth, that is, the best and the worst experiences conceived of by the religious imagination. Religion provides a culturally and traditionally accepted set of words that are used in ordinary discourse by devoted believers and non-believers.

Repetition is often used to strengthen the message, with identical or similar words or phrases. Remarks such as "It is unbelievable"; "It is outside comprehension"; and "It is impossible to understand for others" underline that the experiences of living with a spouse with YO-FTD dementia are outside what is considered a normal and expected life course. Other words and phrases are also used to emphasize the impact of the drastic experience: "It is a disaster", "a slow death". The significant metaphors are elaborated and related to the main theme of the study.
Adding to the problems and barriers of communicating the situation to others are the societal norms of love and duty in marriage, including being a faithful, caring and patient partner on good days as well as bad ones, in sickness and in health. ${ }^{48}$ The norms for not seeking a divorce when the spouse or partner has a serious illness seem to be very strict; however, this is a field shielded by taboos and ethically problematic to study.

Metaphors indicating the spouse's totally transformed personality and loss of roles - as referred to by the metaphor "like a child" - remove the person from a relationship of love and equality. The spouse becomes a qualitatively different person, without reason and responsibility, in a way that the word patient does not imply. Patient encompasses thousands of diagnoses ${ }^{49}$ with many grades of seriousness. By contrast, a child is a more definite categorical metaphor, and the word must be avoided by others, health personnel as well as family and friends. It is demeaning and detracts the life history from the person with dementia. The incorporated reactions, preferences and habits of a long life are what healthcare and social services staff should consider in order to provide appropriate person-centred care. ${ }^{28}$ Nevertheless, for some of the wives in our study, the word child condenses the essence of their new roles, relationship with and responsibilities to their ill husband. The word accentuates the similarities between caregiving to children and to husbands with dementia and the continuity of the female roles. The wives pointed to the overload of work and responsibility they experience when they provide care in addition to carrying out the "adult" roles of their spouse.

Compared to people with Alzheimer's disease (AD), receiving a confirmed diagnosis of young-onset dementia takes longer time. ${ }^{9}$ The diagnostic processes are complicated, both for people with YO-AD dementia and those with YO-FTD dementia. ${ }^{7,14,50}$ The spouses/family carers experience heavy caring strain as well as a reduced quality of life, ${ }^{51,52}$ which often exceed those for people with $\mathrm{AD} .^{53}$ The age and the symptoms of YO-FTD, the personality changes, abnormal behaviour and lack of insight, seem to make the disease improbable, even improper for the carers.

Thus, for many reasons, to communicate the misery of the spouse's experiences is difficult and encounters many barriers, such as the ignorance that dementia can strike younger people, the stigma and shame surrounding the illness, and the lack of understanding even among family 
members and friends. ${ }^{2}$ In summary, the plights of the spouses of people with YO-FTD are felt to be outside understanding, shared experiences and communication. The spouses may need - and seek - metaphors to describe their thoughts and feelings.

Caring for family members with dementia is called "emotion work". 54 The care is characterized by "putting on" a positive attitude, placing the person with dementia first, avoiding conflict and trying to react "the right way". The caring situation implies - as we have documented verbal aggression, fear, fatigue and isolation, and risks for responding "the wrong way". The emotional pressure of neglecting one's own needs and suppressing natural and reasonable reactions is intense and relentless. Our study reveals how metaphors can be a way of expressing emotions when the situation is felt to be intolerable.

In most studies concentrating on family caring for people with dementia, the person with dementia is in the focus. One aim is to identify their needs for adequate support. The caregivers are examined in their caring role and presented with the reactions and stress related to the caring tasks. How they experience their identity, individuality and interests is rarely focused on. Our study, concentrating on the use of metaphors in the spouses' narratives, has revealed how pivotal the loss of self is for the caring spouse. "The self" enters the stage as a primary figure, the central character in the carer's own story, besides the caring role. Several studies have explored the caring resources among spouses. Important questions are: What are their strengths and limits, and when might others - public health - must supplement or take over the care for the spouse with dementia? We have shown how the spouses long for their former "selves". Many are still rather young, and they may have foreseen many years of life ahead of them and a future with "normal" ageing 55 in the third and fourth ages. ${ }^{1}$ As widows or widowers, they are losing not only their spouse but also the togetherness of "the We"48 expected to endure into old age.

Research on private carers for people with dementia often includes mixed samples of caregivers and/or people with different types of dementia. The group of people with YOD encompasses different types of dementia, as previously reported. Also, the "caregivers" or "family caregivers" are mixed groups of spouses and children of both sexes, husbands and wives, daughters and sons, sometimes grandchildren and others. These caregiving relationships are influenced by gender and generational related norms. ${ }^{56}$ Women have traditionally assumed greater obligations to be carers than men, and this is also the case concerning spouses of people with dementia. ${ }^{57}$ The cohabitating spouses have 24/7 caregiving responsibilities - day and night - while adult children, living in separate households, may have several other pressing obligations: their own spouses, children and work. ${ }^{20}$ Their care will be more distanced, and qualitatively different from the care given by spouses. ${ }^{58}$

In a study of spousal caregivers, ${ }^{59}$ the researchers emphasized the importance of differentiating between diagnostic groups among the patients when focusing on caregivers' reactions. Correspondingly, it is necessary to differentiate between the caregivers' relationships to the person with dementia. The duty to continue caring, the involvement, the caring burden, resilience and expected persistence will differ greatly, as well as the resources and willingness to provide extensive care. The public care and health services must be person-centred not only regarding the patient but also to the caregiver. In the care for people with dementia living at home with private caregivers, the service and health personnel are relating to interdependent social relations. The spousal care is vital for quality of life for both partners. Endurance and resilience should be supported with a person-centred concern and relief also for the caregiving spouse. Listening to their stories and the metaphors applied is the key to necessary knowledge. Metaphors open for recognizing the caregivers' emotions, their strength and content. Sensitivity to metaphors among the public caregivers, as a lens, open up for more detailed stories about needs and wishes. The personnel will have to translate and connect this information into adequate services and support.

Studies have documented that, in addition to general services like home nurses and home help, an appreciated service for the family carers/spouses of people with YOD is day care one or several days a week. ${ }^{60,61}$ The Norwegian concept for these services is Avlastning a metaphor meaning relief; reducing the load, taking the burden away. The participants often wish for more support: more activities, more hours, days, weekends and holidays. ${ }^{60}$ Day care preserves a sense of continuity in home life and offers the spouses "free time". In addition, intermittent stays in a nursing home are greatly valued, but the transitions between home and institution may be problematic. A successful service for people with dementia is "support contact", 60 which involves a person paid by the municipalities to visit the ill spouse or take him or her out for individually chosen activities. This tailored service is 
also an important form of relief for the carers. All services that provide the carers with some "free time" to be themselves and reduce their caring tasks and responsibilities are needed. Our study of metaphors attests to how intensely they need such relief.

\section{Strengths and Limitations}

The hermeneutic method in our narrative study has provided rich material for highlighting the experiences of spouses of people with YO-FTD, by analyses of their use of metaphors. The strength of our study is showing how metaphors provide opportunities for condensed and figurative expressions of emotions and experiences, especially those that are difficult to convey with other words. The spouses of people with YO-FTD endure extraordinary caring challenges, and metaphors provide "verbal pictures" for their plights. Even if spouses of people with YO-FTD are rather few, our study of their experiences gives knowledge about exceptional life courses with very extensive and stressing caring tasks, and how they are handled by using metaphors. Dementia develops over a long time, in different stages. Transitions, like departing when the spouse with dementia moves into a nursing home, imply great challenges for both spouses, and release strong emotional reactions. We have included participants who have had these experiences, to include also the later stages of dementia.

Our analysis of metaphors has limitations. When the aim of research is to gain more detailed knowledge about the life situation of spouses of people who have YO-FTD and their specific needs for care and support, other qualitative methods may be more suitable. Such studies may also be combined with quantitative studies. Statistically, the findings of our study cannot be generalized, but we argue that our findings will be transferable ${ }^{62}$ to other spouses of people with YO-FTD and, in some aspects, also to other caregivers of people with young-onset dementia.

\section{Conclusion}

Metaphors are verbal pathways to meaning and messages, especially concerning emotions and the strengths of emotions. In the case of spouses of people with YO-FTD, complex and strong emotions in extraordinary life circumstances with great caring strain are very difficult to communicate. Metaphors provide important clues to the spouses' deepest feelings and needs. Thus, health personnel should listen to the ontological metaphors used by spouses of people with YO-FTD and consider them important clues to their wishes in order to tailor person-centred assistance to the carers.

\section{Acknowledgments}

The authors wish to thank the participants for sharing their experiences, along with the Research Council of Norway, which supported the study. The authors also want to thank Anne-Lise Eriksen, who transcribed the interviews.

\section{Disclosure}

The authors report no conflicts of interest for this work.

\section{References}

1. Laslett P. A fresh map of life, the emergence of the third age. N Statesman Soc. 1989;2:34-35.

2. Johannessen A, Helvik AS, Engedal K, Thorsen K. Experiences and needs of spouses of persons with young-onset frontotemporal lobe dementia during the progression of the disease. Scand J Caring Sci. 2017;31(4):779-788. doi:10.1111/scs.12397

3. WHO. Dementia; 2020. Available from: www.who.int/news-room /fact-sheets/detail/dementia. Accessed October 01, 2020.

4. Engedal K, Haugen PK. Demens: Sykdommer, Diagnostikk Og Behandling [Dementia: Disease, Diagnostics and Treatment]. Norway, Tønsberg: Publisher Ageing and Health; 2018.

5. Johannessen A, Engedal K, Haugen PK, Dourado MC, Thorsen K. Coping with transitions in life: a four-year longitudinal narrative study of single younger people with dementia. J Multidiscip Health. 2019;12:479-492. doi:10.2147/JMDH.S208424

6. Thorsen K, Dourado MCN, Johannessen A. Developing dementia: the existential experience of the quality of life with young-onset dementia - a longitudinal case study. Dementia Lond. 2018;19 (3):878-893. doi:10.1177/1471301218789990

7. Draper B, Cations M, White F, et al. Time to diagnosis in youngonset dementia and its determinants: the INSPIRED study. Int J Geriatr Psychiatry. 2016;31(11):1217-1224. doi:10.1002/ gps. 4430

8. van Vliet D. Young Onset Dementia: Characteristics and Impact [Doctoral Thesis]. Maastricht: Department of Psychiatry and Neuropsychology, School for Mental Health and Neuroscience, Maastricht University; 2012.

9. van Vliet $\mathrm{D}$, de Vugt ME, Bakker $\mathrm{C}$, et al. Time to diagnosis in young-onset dementia as compared with late-onset dementia. Psychol Med. 2013;43(2):423-432. doi:10.1017/S0033291712001122

10. Zhu XC, Tan L, Wang HF, et al. Rate of early onset Alzheimer's disease: a systematic review and meta-analysis. Ann Transl Med. 2015;3(3):38. doi:10.3978/j.issn.2305-5839.2015.01.19

11. Kvello-Alme M, Bråthen G, White LR, Sando SB, Knopman D. The prevalence and subtypes of young onset dementia in Central Norway: a population-based study. J Alzheimers Dis. 2019;69(2):479-487. doi:10.3233/JAD

12. Pasquier F, Petit H. Frontotemporal dementia: its rediscovery. Eur Neurol. 1997;38(1):1-6. doi:10.1159/000112894

13. Onyike CU, Diehl-Schmid J. The epidemiology of frontotemporal dementia. Int Rev Psychiatr. 2013;25(2):130-137. doi:10.3109/ 09540261.2013 .776523

14. Rosness TA, Haugen PK, Passant U, Engedal K. Frontotemporal dementia: a clinically complex diagnosis. Int J Geriatr Psychiatry. 2008;23(8):837-842. doi:10.1002/gps.1992 
15. Haugen PK. Demens Før 65 Ar. Fakta, Utfordringer Og Anbefalinger [Dementia Before the Age of 65 Years. Facts, Demands and Recommendations]: Rapport.Utviklingsprogram Om Yngre Personer Med Demens, Demensplan 2015 [Report. A Development Plan for People with Young-Onset of Dementia, Dementiaplan 2015]. Tønsberg: Forlaget Aldring og helse [Publisher Ageing and Health]; 2012.

16. Gentry MT, Lapid MI, Syrjanen J, et al. Quality of life and caregiver burden in familial frontotemporal lobar degeneration: analyses of symptomatic and asymptomatic individuals within the LEFFTDS cohort. Alzheimers Dement. 2020;16(8):1115-1124. doi:10.1002/ alz. 12095

17. Kimura NR, Simões JP, Santos RL, et al. Young- and late-onset dementia: a comparative study of quality of life, burden, and depressive symptoms in caregivers. $J$ Geriatr Psychiatry Neurol. 2020;089198872093335. doi:10.1177/0891988720933355.

18. van Vliet D, de Vugt ME, Bakker C, Koopmans RT, Verhey FR. Impact of early onset dementia on caregivers: a review. Int $J$ Geriatr Psychiatry. 2010;25(11):1091-1100. doi:10.1002/gps.2439

19. Kaiser S, Panegyres PK. The psychosocial impact of young onset dementia on spouses. Am J Alzheimers Dis Other Demen. 2006;21 (6):398-402. doi:10.1177/1533317506293259

20. Johannessen A, Engedal K, Thorsen K. Coping efforts and resilience among adult children who grew up with a parent with young-onset dementia: a qualitative follow-up study. Int J Qual Stud Health WellBeing. 2016;11:30535. doi:10.3402/qhw.v11.30535

21. Caceres BA, Frank MO, Jun J, Martelly MT, Sadarangani T, de Sales PC. Family caregivers of patients with frontotemporal dementia: an integrative review. Int $J$ Nurs Stud. 2016;55:71-84. doi:10.1016/j.ijnurstu.2015.10.016

22. Nunnemann S, Kurz A, Leucht S, Diehl-Schmid J. Caregivers of patients with frontotemporal lobar degeneration: a review of burden, problems, needs, and interventions. Int Psychogeriatr. 2012;24 (9):1368-1386. doi:10.1017/S104161021200035X

23. Hvidsten L, Engedal K, Selbæk G, Wyller TB, Benth JŠ, Kersten H. Quality of life in people with young-onset dementia: a Nordic two-year observational multicenter study. J Alzheimers Dis. 2019;67 (1):197-210. doi:10.3233/jad-180479

24. Massimo L, Evans LK, Benner P. Caring for loved ones with frontotemporal degeneration: the lived experiences of spouses. Geriatr Nurs (Minneap). 2013;34(4):302-306. doi:10.1016/j.gerinurse.2013.05.001

25. Riedijk S, Duivenvoorden H, Rosso S, Van Swieten J, Niermeijer M, Tibben A. Frontotemporal dementia: change of familial caregiver burden and partner relation in a Dutch cohort of 63 patients. Dement Geriatr Cogn Disord. 2008;26(5):398-406. doi:10.1159/ 000164276

26. Rasmussen H, Hellzen O, Stordal E, Enmarker I. Family caregivers experiences of the pre-diagnostic stage in frontotemporal dementia. Geriatr Nurs. 2019;40(3):246-251. doi:10.1016/j.gerinur se.2018.10.006

27. Cabote CJ, Bramble M, McCann D. Family caregivers' experiences of caring for a relative with younger onset dementia: a qualitative systematic review. J Fam Nurs. 2015;21(3):443-468. doi:10.1177/ 1074840715573870

28. Sharma T, Bamford M, Dodman D. Person-centred care: an overview of reviews. Contemp Nurse. 2015;51(2-3):107-120. doi:10.1080/ 10376178.2016.1150192

29. Ricoeur P. The Rule of Metaphor: The Creation of Meaning in Language. London and New York: Psychology Press; 2003.

30. Lakoff G, Johnson M. Metaphors We Live By. London: University of Chicago Press; 1980.

31. Federel M, Eftedal CI Sammenligning, metafor og klisje' [Comparison, metaphor and cliché]. Nasjonal digital læringsarena [National digital Learning arena]; 2018. Available from: https://ndla.no/subjects/sub ject:19/topic:1:195257/topic:1:2845/resource:1:2027?filters=urn:filter: f4581340-52f1-435d-8f99-d5de4e123f70. Accessed October 01, 2020.
32. Sacks S, ed. On Metaphor. Chicago: University of Chicago Press; 1979.

33. Tay D. Using metaphor in health care. Mental health interventions. In: Demjén Z, Semino E, editors. The Routledge Handbook of Metaphor and Language. Routledge; 2017:370-384.

34. McMullen LM. Studying the use of figurative language in psychotherapy: the search for researchable questions. Metaphor Symbol. 1996;11(4):241-255. doi:10.1207/s15327868ms1104_1

35. Spiggle S. Analysis and interpretation of qualitative data in consumer research. J Consum Res. 1994;21(3):491-503. doi:10.1086/209413

36. Sontag S. Illness as Metaphor. New York: Farrar, Straus and Giroux; 1978.

37. Johannessen A, Engedal K, Thorsen K. Adult children of parents with young-onset dementia narrate the experiences of their youth through metaphors. $J$ Multidiscip Healthc. 2015;8:245-254. doi:10.2147/JMDH.S84069

38. Mullen M. Putting it in context: metaphor and psychotherapy. In: Gibbs RW, editor. The Cambridge Handbook of Metaphor and Thought. Cambridge: Cambride University Press; 2008:397-411.

39. Low G, Deignan A, Cameron L, Todd Z. Researching and Applying Metaphor in the Real World. John Benjamins Publishing: The open university; 2010.

40. Wertz FJ, Charmaz C, McMullen LM, Josselson R, Anderson R, Emalinda McSpadden E. Five Ways of Doing Qualitative Analysis: Phenomenological Psychology, Grounded Theory, Discourse Analysis, Narrative Research, and Intuitive Inquiry. New York: Guilford Press; 2011.

41. Lindseth A, Norberg A. A phenomenological hermeneutical method for researching lived experience. Scand J Caring Sci. 2004;18 (2):145-153. doi:10.1111/j.1471-6712.2004.00258.x

42. Mishler EG. The analysis of interview-narratives. In: Sarbin TR, editor. Narrative Psychology: The Storied Nature of Human Conduct. Praeger Publishers/Greenwood Publishing Group; 1986:233-255.

43. Kvale S. The qualitative research interview. J Phenomenol Psychol. 1983;14(1-2):171-196. doi:10.1163/156916283X00090

44. Kvale S. To validate is to question. In: Kvale S, editor. Issues of Validity in Qualitative Research. Lund: Studentlitteratur [Studentliterature]; 1989:73-92.

45. Denzin N, Lincoln Y. The SAGE Handbook of Qualitative Research. London: Sage Publications Ltd; 2011.

46. Steger T. The stories metaphors tell: metaphors as a tool to decipher tacit aspects in narratives. Field Methods. 2007;19(1):3-23. doi: $10.1177 / 1525822 \times 06292788$

47. World Medical Association. Declaration of Helsinki; 2013. Available from: http://www.wma.net/en/30publications/10policies/b3/index. html. Accessed October 01, 2020.

48. Thorsen K, Tretteteig S. Å miste sin nærmeste: å tape et «vi» og seg selv [To loose the partner: to loose a 'We' and oneself]. Tidsskriftet Aldring Og Helse. 2019;23(3):32-34.

49. WHO. International Classification of Diseases and Related Health Problems, ICD-10. Geneva: World Health Organization; 2007.

50. O’Malley M, Parkes J, Stamou V, LaFontaine J, Oyebode J, Carter J. Young-onset dementia: scoping review of key pointers to diagnostic accuracy. BJ Psych Open. 2019;5(3):e48. doi:10.1192/bjo.2019.36

51. Chow TW, Pio FJ, Rockwood K. An international needs assessment of caregivers for frontotemporal dementia. Can J Neurol Sci. 2011;38 (5):753-757. doi:10.1017/s0317167100054147

52. Oyebode JR, Bradley P, Allen JL. Relatives' experiences of frontalvariant frontotemporal dementia. Qual Health Res. 2013;23 (2):156-166. doi:10.1177/1049732312466294

53. Uflacker A, Edmondson MC, Onyike CU, Appleby BS. Caregiver burden in atypical dementias: comparing frontotemporal dementia, Creutzfeldt-Jakob disease, and Alzheimer's disease. Int Psychogeriatr. 2016;28(2):269-273. doi:10.1177/104973231 2466294 
54. Herron RV, Funk LM, Spencer D. Responding the 'wrong way': the emotion work of caring for a family member with dementia. Gerontologist. 2019;59(5):e470-e478. doi:10.1093/geront/gnz047

55. Hagestad G. Interdependent lives and relationships in changing times. A life course view of families and aging. In: Setters R, editor Invitation to the Life Course: Toward New Understandings in Later Life. New York: Baywood Publishing Company Inc.; 2003.

56. Thorsen K. The Relation Specific Care and It's Meaning. GerArt Gerontological Articles. Oslo: NOVA. (Oslo Metropolitan University); 1995.

57. Arbel I, Bingham KS, Dawson DR, Heyn PC. A scoping review of literature on sex and gender differences among dementia spousal caregivers. Gerontologist. 2019;59(6):e802-e815. doi:10.1093/geront/gny177

58. Tretteteig S, Thorsen K, Rokstad AMM. Pårørendes erfaringer av kvalitet $\mathrm{i}$ helse- og omsorgstjenester til personer med demens og deres pårørende. En Longitudinell Narrativ Studie. 2019;4:56-65.
59. de Vugt ME, Riedijk SR, Aalten P, Tibben A, van Swieten JC, Verhey FR. Impact of behavioural problems on spousal caregivers: a comparison between Alzheimer's disease and frontotemporal dementia. Dement Geriatr Cogn Disord. 2006;22(1):35-41. doi: $10.1159 / 000093102$

60. Johannessen A, Engedal K, Thorsen K. Family carers of people with young-onset dementia: their experiences with the supporter service. Geriatrics. 2016;1(4):28. doi:10.3390/geriatrics1040028

61. Tretteteig S, Vatne S, Rokstad AM. The influence of day care centres for people with dementia on family caregivers: an integrative review of the literature. Aging Ment Health. 2016;20(5):450-462. doi:10.1080/13607863.2015.1023765

62. Malterud K. Qualitative research: standards, challenges, and guidelines. Lancet. 2001;358(9280):483-488. doi:10.1016/S01406736(01)05627-6
Journal of Multidisciplinary Healthcare

\section{Publish your work in this journal}

The Journal of Multidisciplinary Healthcare is an international, peerreviewed open-access journal that aims to represent and publish research in healthcare areas delivered by practitioners of different disciplines. This includes studies and reviews conducted by multidisciplinary teams as well as research which evaluates the results or conduct of such teams or healthcare processes in general. The journal

\section{Dovepress}

covers a very wide range of areas and welcomes submissions from practitioners at all levels, from all over the world. The manuscript management system is completely online and includes a very quick and fair peer-review system. Visit http://www.dovepress.com/testimonials. php to read real quotes from published authors. 